\title{
NESTING ECOLOGY OF YELLOW WARBLERS (DENDROICA PETECHIA) IN MONTANE CHAPARRAL HABITAT IN THE NORTHERN SIERRA NEVADA
}

\author{
Diana L. Humple ${ }^{1}$ and Ryan D. Burnett ${ }^{1,2}$
}

\begin{abstract}
The Yellow Warbler (Dendroica petechia) is considered a riparian specialist in much of western North America, but in California it also breeds in a second habitat type: montane chaparral of the Sierra Nevada and southern Cascades. We monitored Yellow Warbler nests in montane chaparral and assessed their poorly known nesting ecology in this habitat. We also conducted point counts in upland habitat throughout the region. We determined habitat associations for Yellow Warblers based on nest site and point-count vegetation data; nests were predominantly in bush chinquapin (Chrysolepis sempervirens) and greenleaf manzanita (Arctostaphylos patula), and point-count abundance was most strongly associated with high overall shrub cover. The importance of montane chaparral for a number of shrubdependent Sierran birds is well documented, yet the chaparral is threatened by various practices including fire suppression, closed-canopy-focused forest management, and understory fuels-reduction treatments. Although Yellow Warblers are far more abundant in wet mountain meadow riparian habitat in the region, we recommend that management of montane chaparral habitat consider this species and the requirements of other shrub-nesting birds.
\end{abstract}

Key words: Yellow Warbler, montane chaparral, nesting ecology, xeric scrub, northern Sierra Nevada.

Montane chaparral habitat is an ecologically important yet often overlooked component of the Sierra Nevada ecosystem. It occurs in small to relatively large openings in the otherwise continuous forested landscape. These shrubdominated areas occur either as climax conditions in areas that naturally do not support forest or as early successional stages following major disturbance. Historically, this predominantly disturbance-dependent habitat was naturally regenerated by frequent fire; more recently, it is often created by even-aged timber harvest (i.e., clear-cutting) that removes the majority of forest canopy. The importance of early successional habitats for birds in western forests is well documented (Raphael et al. 1987, Verner and Larson 1989, Hutto 1995, Altman and Hagar 2007). Montane chaparral is host to numerous songbird species that are rare to absent in adjacent continuous conifer-dominated habitats. Typical bird species that breed in montane chaparral habitats in the northern Sierra Nevada include Mountain Quail (Oreortyx pictus), Dusky Flycatcher (Empidonax oberholseri), MacGillivray's Warbler (Oporornis tolmiei), Fox Sparrow (Passerella iliaca), Green-tailed Towhee (Pipilo chlorurus), and Spotted Towhee (Pipilo maculatus).
Fire suppression, closed-canopy-focused forest management, and understory fuels-reduction treatments are current threats to montane chaparral habitat. Fire-return intervals have been lengthened, and the area affected by wildfire annually has been dramatically reduced in the interior mountains of California over the past century (Taylor 2000, Taylor and Skinner 2003, Stephens et al. 2007). Tree densities have increased, reducing the shrub understory, and montane chaparral areas have been converted to forest (Vankat and Major 1978, Nagel and Taylor 2005). Although this is partly a natural process, due to management practices this conversion is likely happening at an accelerated rate. Outside of small-group selections $(<1 \mathrm{ha})$, clear-cutting is no longer employed on national forest land in the Sierra Nevada, and the majority of forest fuels-reduction treatments maintain a minimum of $40 \%$ canopy cover (HFQLG 1999, SNFPA 2004). Many fuels-reduction treatments are implemented in chaparral with the focus on removing shrubs and at times promoting conversion to forest through active conifer plantings.

Yellow Warblers (Dendroica petechia) are generally considered riparian specialists in California and much of western North America

\footnotetext{
${ }^{1}$ PRBO Conservation Science, 3820 Cypress Drive \#11, Petaluma, CA 94954
}

22Corresponding author. E-mail: rburnett@prbo.org 


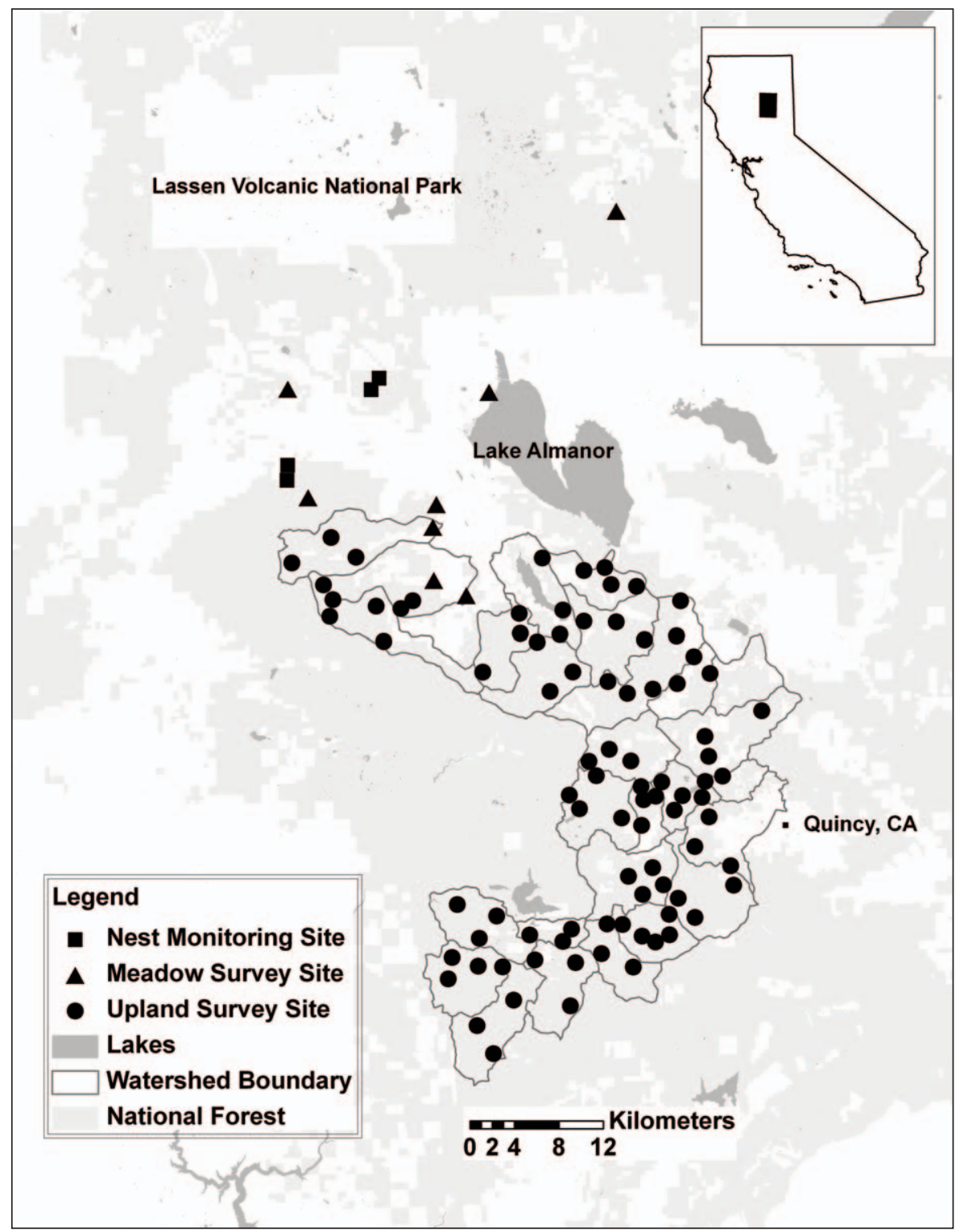

Fig. 1. Monitoring and survey sites in Lassen National Forest and on adjacent private lands, northern Sierra Nevada, California.

(Heath 2008) and have even been described as riparian obligates (Grinnell and Miller 1944). Elsewhere in their breeding range they are found in fairly diverse habitats (Lowther et al. 1999). In parts of the Cascades and Sierra Nevada of California, Yellow Warblers are also found breeding in montane chaparral (Grinnell et al. 1930, Beedy and Granholm 1985, Raphael et al. 1987, Gaines 1992, Siegel and DeSante 2003, Heath 2008), in areas completely disassociated from riparian habitat. However, their natural history in this habitat has received little attention, and published data on their nesting ecology here is scarce.

We conducted nest monitoring in montane chaparral in the northern Sierra Nevada from 2002 to 2005 and verified Yellow Warblers breeding in this habitat. We present nesting ecology data herein for a small sample of nests in an effort to more fully document Yellow Warbler 
breeding biology and ecology in an important habitat type in the region. We also present information on overall habitat associations of Yellow Warblers in the region based on large-scale point-count data collected from 2003 to 2006.

\section{STUdy AREA}

We located and monitored nests of shrubassociated songbirds on 4 conifer plantations on the Almanor Ranger District of Lassen National Forest, at the intersection of the northern Sierra Nevada and the southern Cascade Mountains of northeastern California in Tehama and Plumas counties (Fig. 1). The study sites were characterized by multiple shrub species interspersed with rows of planted ponderosa pine (Pinus ponderosa) and white fir (Abies concolor) saplings, much as is characteristic of the montane chaparral or mixed chaparral plant communities. Dominant plants included greenleaf manzanita (Arctostaphylos patula), mountain whitethorn (Ceanothus cordulatus), bush chinquapin (Chrysolepis sempervirens), and pinemat manzanita (Arctostaphylos nevadensis). Each of the plantations had been clear-cut between 1987 and 1989. The clear-cuts ranged from 10 to 50 ha, in which we overlaid study plots of 10 to $23 \mathrm{ha}$; plot size varied depending upon differences in vegetation and in subsequent avian density. Plots were selected based on their stage of regeneration and were not chosen randomly due to logistical constraints (many chaparral areas were impenetrable or too steep). However, we believe the plots are representative of 15-20-year-old plantations within the mixed conifer zone of the region. Two of the plots (Carter Meadow Road, elevation $1600 \mathrm{~m}$ ) were clear-cut in 1989, replanted in 1992, and conifer-released by hand (i.e., shrubs surrounding planted conifers were removed with chainsaws) in 2000. The other 2 plots (Stover Mountain, elevation $1750 \mathrm{~m}$ ) were clearcut in 1987, replanted in 1989, and varied in release treatments, with herbicide used on one plot and mastication used on portions of the other. The 2 pairs of plots were $9.5 \mathrm{~km}$ apart; each plot was most similar to and was $1 \mathrm{~km}$ apart from its partner plot. The Carter Meadow Road plots had a greater diversity of shrub species, while the Stover Mountain plots were dominated by greenleaf manzanita and bush chinquapin. The Carter Meadow Road plots were at an earlier successional stage, with ponderosa pine saplings at most $3 \mathrm{~m}$ tall, while the Stover Mountain plots contained planted pines as tall as $8 \mathrm{~m}$. Because of the low densities of Yellow Warblers and our interest in their breeding biology, their territories adjacent to our study plots were also monitored.

A landscape-scale study of the landbird community was also conducted from 2003 to 2006 across upland habitat on the west slope of the Sierra Nevada in the Lassen and Plumas national forests. Upland habitat ranged from dense conifer forest to open mixed conifer forest with chaparral understory, with some individual points consisting predominantly of chaparral with little forest canopy. A total of 1176 upland point-count stations were visited across an elevational gradient of 944-2140 m (Fig. 1). Riparian habitat, which makes up about $1 \%$ of the study area landscape, was specifically avoided; upland sites were established at least $50 \mathrm{~m}$ from riparian or meadow habitat, with the vast majority $>1 \mathrm{~km}$ away. We also investigated bird communities in riparian habitat in 8 willow-filled wet mountain meadows, which were located in the Lassen National Forest and on adjacent private lands across an elevational gradient of 1300-1850 m (Fig. 1), giving us a total of 88 additional points.

\section{Methods}

Nest plots were visited 2-3 times weekly between early May and July, from 2002 to 2005. Nest finding and monitoring followed specific guidelines outlined in Martin and Geupel (1993). Yellow Warbler nests were located during construction, egg-laying, or incubation by observing parental behavior. Nests were checked every 2-4 days until nestlings had fledged or the nest had failed. Careful attention was given to minimizing human disturbance of active nests.

After a nesting attempt terminated, we measured characteristics of the nest substrate and surrounding vegetation. We used a slightly modified version of the Breeding Biology Research and Monitoring Database (BBIRD) method for vegetation measurements (Martin and Conway 1995). Vegetation sampling was centered on the nest and evaluated across a 5-mradius plot for shrub, herbaceous plant, and nonvegetated (e.g., bare ground) layers and evaluated across an 11.3-m-radius plot for trees and saplings (defined as trees with $<8 \mathrm{~cm} \mathrm{dbh}$ ). 
Sampling included ocular estimates of percent cover of shrubs, forbs, and each plant species within those categories, as well as of bare ground, logs, and litter. For each shrub species, average height was estimated, maximum height was measured, and number of stems at $10 \mathrm{~cm}$ above ground level was counted. We also collected this vegetation data at 30 randomly selected nonuse sites per plot (totaling 120 sites) in 2003 to randomly quantify the vegetation on the plots and to compare it to vegetation at the nest sites. These locations were selected using the random-point generator within the AlaskaPak extension in an ArcView GIS environment (ESRI 2000).

Standardized 5-minute fixed-radius multipledistance-band point-count censuses (Ralph et al. 1993, Buckland et al. 1993) were conducted at 1176 upland point-count stations across 92 transects and at 88 stations in 8 wet meadows. All were surveyed each year from 2004 to 2006 , with $70 \%$ of these points also surveyed in 2003 . For upland site selection, 3 point-count transects consisting of 12 points each were established in each of 26 California planning watersheds (CalWater 1999) in the study area using a random starting point generated in a GIS environment (ArcView 3.2a; ESRI 2000); 11 additional points per transect were established at approximately 250-m intervals following a random compass bearing, resulting in 936 point-count stations. An additional 168 points (14 transects) within areas slated for silvicultural treatments and 72 points surrounding known Spotted Owl (Strix occidentalis) nesting or roosting locations were also included in the upland sample. At each point-count station, we conducted a modified relevé vegetation survey (Ralph et al. 1993), in which biologists estimated percent cover of vegetation by class (e.g., tree, shrubs, forbs), percent cover of each plant species, and mean maximum height for the dominant species within each class, over a 50-m radius. Eight riparian transects, totaling 88 points with points spaced 200-250 m apart, were selected for longterm monitoring from 15 wet mountain meadows inventoried on the Almanor Ranger District. These were monitored from 2004 to 2007. All upland and riparian points were visited twice per year between mid-May and mid-July.

\section{Statistical Analyses}

To calculate nest success, we used a modified Mayfield method (Mayfield 1961, 1975), which considers the number of days each nest was under observation, thereby eliminating potential underestimation of losses because of nests found late in the nesting cycle. We defined the nesting period as beginning on the day the first egg was laid and ending on the day of nest failure or departure of the first nestling. We used period lengths based on our data from these study sites: 2 days for laying ( 1 day fewer than the mean clutch size), 11.5 days for incubation, and 10 days for the nestling period. Compared to period lengths for Yellow Warblers from other studies, our laying period was shorter, incubation period was comparable, and nestling period was comparable or longer (Ehrlich et al. 1988, Lowther et al. 1999).

We compared 10 habitat characteristics at Yellow Warbler nest sites to characteristics at random (nonuse) sites on each study plot using 2 -tailed $t$ tests. Variables were selected $a$ priori, based on our experience of observing this species in montane chaparral habitats. Variables included bush chinquapin cover, bush chinquapin maximum height, bush chinquapin average height, mountain whitethorn cover, greenleaf manzanita cover, greenleaf manzanita maximum height, greenleaf manzanita average height, total shrub cover, log cover, and number of ponderosa pine saplings. Although multiple tests inflate the tablewide error rate (Rice 1989), we chose not to use Bonferroni corrections in our interpretation of $P$ values, following instead the recommendations of Moran (2003): we report exact $P$ values, used an uncorrected $\alpha$ of 0.05 , and interpret the habitat-use results in the context of biological significance.

Mean abundance of Yellow Warblers using point-count data is presented as number of detections per point per visit within $50 \mathrm{~m}$ of observers. We selected 10 a priori vegetation variables at upland point-count stations and determined pairwise correlations for each with mean Yellow Warbler abundance averaged across all years in which each site was visited. These variables were tree basal area; maximum shrub height; shrub species richness; and respective covers of combined trees, combined shrubs, mountain whitethorn, greenleaf manzanita, bush chinquapin, deerbrush (Ceanothus integerrimus), and Sierra gooseberry (Ribes roezlii). Using negative binomial regression, we determined the significance of all variables having a correlation coefficient $>0.20$. We developed a multivariate model by placing each of 


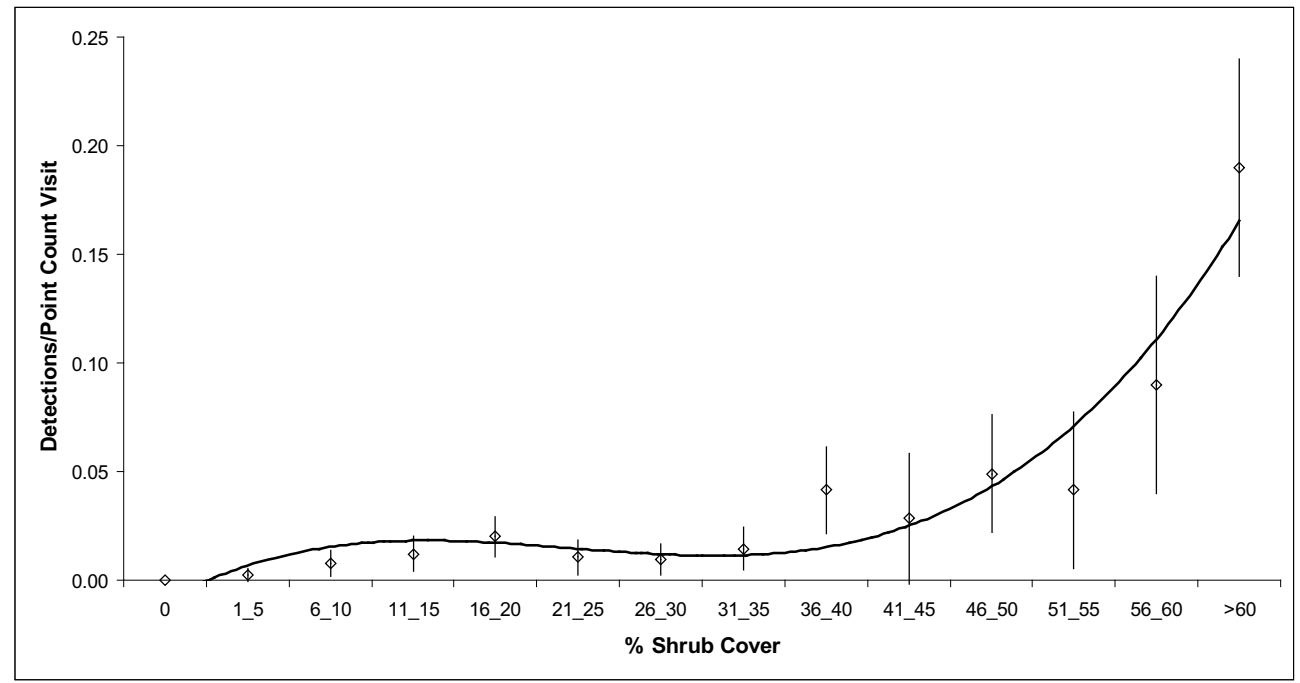

Fig. 2. Yellow Warbler detections (and standard errors) within $50 \mathrm{~m}$ from point along shrub-cover-gradient upland point-count stations in the northern Sierra Nevada, California.

the variables with a significant effect in a backward stepwise negative binomial regression procedure with the threshold for inclusion in the final model set at $\alpha=0.05$.

\section{RESULTS}

We found and monitored to completion 9 Yellow Warbler nests in montane chaparral in 2003-2005; none were found during the first year of the study, although Yellow Warblers were presumed breeding at the plots. Mayfield total nest survival was 0.345 , and daily nest survival was $0.956(\mathrm{SE}=0.019)$. Four nests fledged young, 4 were depredated (1 during incubation and 3 either during incubation or soon after hatching), and 1 was abandoned with eggs (either during laying or incubation). A single nest was parasitized by a Brownheaded Cowbird (Molothrus ater); the nest was depredated either with 2 host eggs and a single cowbird egg or with recently hatched young. Clutch completion date for these chaparral nests fell between 8 June and 22 June $(n=$ 9). Clutch size ranged from 2 to 4 eggs, with a mean of 3.00 (SD $=0.89, n=6)$, for nests with confirmed complete clutch sizes. Successful nests fledged an average of 3.25 young (SD $=0.96, n=4)$.

Eight of the chaparral nests were found in bush chinquapin and one in greenleaf manzanita. At the Carter Meadow Road plots, where all 5 nests were in chinquapin, mountain whitethorn is the most dominant shrub (23\% average shrub cover at nonuse sites), followed by bush chinquapin (14\%) and greenleaf manzanita (8\%). At the Stover Mountain plots, where 3 nests were found in chinquapin and 1 in greenleaf manzanita, greenleaf manzanita is the most dominant shrub (25\%), followed by the lowgrowing pinemat manzanita (13\%) and bush chinquapin (9\%). Mean nest height was 100 $\mathrm{cm}(\mathrm{SD}=20, n=9)$, and ranged from 57 to $130 \mathrm{~cm}$. Mean nest-shrub height was $140 \mathrm{~cm}$ $(\mathrm{SE}=9)$ and ranged from 100 to $190 \mathrm{~cm}$. Five of the 10 Yellow Warbler nest site characteristics examined were significantly different fromand in all cases higher than-those characteristics in nonuse sites: bush chinquapin cover, $34 \%(\mathrm{SE}=7.5)$ versus $11.4 \%(\mathrm{SE}=1.9 ; t=$ $3.08, P=0.003)$; bush chinquapin maximum height, $159.2 \mathrm{~cm}(\mathrm{SE}=8.7)$ versus $66.6 \mathrm{~cm}$ $(\mathrm{SE}=8.0 ; t=3.15, P=0.002)$; bush chinquapin average height, $109.4 \mathrm{~cm}(\mathrm{SE}=9.6)$ versus $50.1 \mathrm{~cm}(\mathrm{SE}=5.7 ; t=2.84, P=0.005)$; greenleaf manzanita maximum height, 160.6 $\mathrm{cm}(\mathrm{SE}=8.4)$ versus $113.0 \mathrm{~cm}(\mathrm{SE}=5.9 ; t=$ $2.19, P=0.03)$; and total shrub cover, $80.7 \%$ $(\mathrm{SE}=3.6)$ versus $56.7 \%(\mathrm{SE}=2.8 ; t=2.29$, $P=0.02)$.

Across the region, Yellow Warblers were the second most abundant species in riparian/ meadow habitat (mean 0.95 birds per point for 
TABLE 1. Reverse stepwise multivariate negative binomial regression model $\left(n=1176\right.$, likelihood ratio $\chi^{2}=$ 108.87, $P=0.000$, pseudo $r^{2}=0.23$ ) predicting Yellow Warbler abundance at upland point-count stations in the Lassen and Plumas National Forests from 2003 to 2006.

\begin{tabular}{lccc}
\hline Variable & $\begin{array}{c}\text { Regression } \\
\text { coefficient }\end{array}$ & SE & $P$ value \\
\hline Total shrub cover & 0.04 & 0.007 & $<0.001$ \\
Mountain whitethorn cover & 0.03 & 0.013 & 0.03 \\
Greenleaf manzanita cover & 0.02 & 0.008 & 0.03 \\
\hline
\end{tabular}

$50-\mathrm{m}$ radius) and only the 27 th most abundant in upland habitat (mean 0.03 birds per point). The highest abundance of Yellow Warblers in any wet meadow point-count transect was 1.92 birds per point. In upland habitat, highest abundance was 0.43 birds per point, on a transect dominated by montane chaparral habitat with a few interspersed conifers. Yellow Warblers were detected within $50 \mathrm{~m}$ of observers at 113 of the 1176 upland point-count stations. Shrub cover at sites where they were detected averaged $40 \%(\mathrm{SE}=2.3)$, while at stations where none where detected, shrub cover averaged $22 \%(\mathrm{SE}=0.6)$. In upland habitat, Yellow Warbler abundance was positively correlated with shrub cover, mountain whitethorn cover, and greenleaf manzanita cover. Total shrub cover had the greatest predictive power (pseudo $\mathrm{R}^{2}$ $=0.21, \chi^{2}=100.66, P<0.001$; Fig. 2 ), above that of greenleaf manzanita cover (pseudo $\mathrm{R}^{2}$ $\left.=0.12, \chi^{2}=59.83, P<0.001\right)$ and mountain whitethorn cover (pseudo $\mathrm{R}^{2}=0.07, \chi^{2}=$ 35.01, $P<0.001)$. These significant variables were moderately intercorrelated, with the strongest correlation occurring between total shrub cover and greenleaf manzanita cover $(\mathrm{R}$ $=0.53, P<0.0001)$. Despite the intercorrelation, all 3 remained significant predictors when considered together (pseudo $\mathrm{R}^{2}=0.23$, $\chi^{2}=108.87, P<0.001$; see Table 1 ), though the variance explained by the multivariate model was only slightly higher than that explained by shrub cover alone.

\section{DisCuSSION}

Although somewhat plastic in breeding habitat throughout much of their range (Lowther et al. 1999), Yellow Warblers in western North America are generally considered more of a riparian specialist (Heath 2008). Montane chaparral is the only other habitat in California in which they breed. This is not an intuitive secondary breeding habitat for Yellow Warblers, nor does the occurrence of Yellow Warblers in chaparral suggest mere overflow of individuals from nearby riparian habitat. Instead, structure of the 2 habitats is dissimilar; montane chaparral is not found in association with riparian areas; and nest placement is remarkably different in the habitats, with riparian breeders often placing their nests in the tree canopy, in willows, or in saplings.

We found total shrub cover to be the most important predictive variable of Yellow Warbler occurrence in upland habitat in this region, with mountain whitethorn cover and greenleaf manzanita cover also potentially important as well. Yellow Warblers are associated with significantly higher shrub cover than 3 of the 4 most common chaparral birds studied here (Dusky Flycatcher, Fox Sparrow, and Green-tailed Towhee); only the cover surrounding MacGillivray's Warbler nests was as high as the cover surrounding Yellow Warbler nests (PRBO unpublished data). We recommend that management actions for Yellow Warblers in montane chaparral habitat promote areas with shrub cover above $40 \%$, as our results suggest a threshold at this level, above which Yellow Warbler abundance increases precipitously. These areas should also contain patches with considerably higher shrub cover, consistent with what Yellow Warblers selected for nest placement. At our nest plots, montane chaparral-breeding Yellow Warblers preferentially placed nests in bush chinquapin, even when the chinquapin was less common than other potential substrates. The lack of a strong relationship of Yellow Warbler abundance with bush chinquapin at our pointcount stations in the region likely reflects chinquapin's greater prevalence at our nest plots than at the slightly lower elevations where most of our point counts occur and where bush chinquapin tends to be far less common. In those lower elevations, Yellow Warblers instead are frequently observed nesting in areas that are dominated by greenleaf manzanita and do not contain bush chinquapin, suggesting they will readily use other shrub species as nest substrate (PRBO unpublished data).

Although our Mayfield nest survival at 34.5\% $(n=9)$ was much lower than Yellow Warbler nest success in riparian habitat in the region $(88.6 \%, n=18$; King et al. 2001), the latter was considered high for an open-cup-nesting songbird and the former comparable to more-typical 
rates (Martin 1992). This nest survival rate in chaparral was lower than survival rates $(42 \%-$ 95\%) summarized in Salgado-Ortiz et al. (2008) for temperate-breeding Yellow Warblers outside of California, and lower than proportional nest success $(66.7 \%)$ found in the region in thinned coniferous forest containing a vigorous shrub layer $(n=6$; Siegel and DeSante 2003). Most studies of this species have found relatively high rates of cowbird parasitism (Ortega 1998, Lowther et al. 1999, Heath 2008, PRBO unpublished data); however, we found a relatively low parasitism rate in our study $(11 \%)$. The distance to preferred cowbird foraging habitat (e.g., grazed pasture) and the relatively small size of these chaparral openings within a greater forested matrix are likely the reasons for the relatively low cowbird abundance and subsequent parasitism rate. We suggest that the landscape context of montane chaparral habitat (e.g., distance to pastures, towns, or large meadows) may significantly influence the susceptibility of Yellow Warblers to parasitism in this habitat type. However, of the 415 open-cup passerine nests in our study in which at least one egg was laid, one of the only 2 nests parasitized was that of a Yellow Warbler, further suggesting anecdotally that cowbirds preferentially parasitize this species even in a habitat where parasitism is rare.

While our study provides some insight into the nesting ecology and habitat associations of Yellow Warblers in montane chaparral in the Sierra Nevada, we recognize the need for further study, particularly for additional nest monitoring. Our sample size of nests is likely too small to offer any real data on parasitism, an important conservation issue for the species. And because chaparral habitat varies throughout the northern Sierra Nevada and with elevation, our results for productivity and nest vegetation associations may not be typical of the region.

Despite the value of this habitat to Yellow Warblers and our suggestion that they be included in the suite of shrub-nesting species that help guide montane chaparral management, we recognize that from a population standpoint, management for Yellow Warblers in the region would be better focused on riparian habitat in wet mountain meadows. In that habitat, Yellow Warbler breeding densities are considerably higher and among the highest recorded in California (Heath 2008, PRBO unpublished data). However, additional information about breeding productivity, parasitism, overall population size, and natal dispersal between habitat types would help us understand the contribution of these chaparral sites to the regional population. This study does not permit us to assess the role despotism-the pushing of young birds into marginal habitat (Rohwer 2004)_might play in Yellow Warbler occurrence in this secondary habitat type. However, observations of after-second-year birds breeding in chaparral in this region and the disassociation of this habitat type with riparian habitat in the region lead us to suspect that spillover effect is not responsible for the species' current distribution in chaparral.

With increasing management attention focused on old-growth attributes of forests in the Sierra Nevada (SNFPA 2004) and public attention focused on reducing the role of fire, there is concern that open-forest habitatsincluding early successional montane chaparral-will decrease in both quantity and quality in the next few decades. Such habitat supports Yellow Warblers and numerous other species not found in forested habitats in the region (e.g., Mountain Quail, Dusky Flycatcher, MacGillivray's Warbler, Fox Sparrow, and Green-tailed Towhee). Management of this often-overlooked habitat is critical for many species, including for the conservation of many shrub-nesting songbirds. Siegel and DeSante (2003) detected 4 times as many Yellow Warblers in thinned versus unthinned Sierran mixed conifer forest plots, and similar patterns for other shrubdependent Sierran birds; thinned areas had reduced canopy cover, reduced density of younger conifers, and increased density of understory shrubs. Raphael et al. (1987) found that Yellow Warbler breeding density increased in postfire sites in the Sierra Nevada as shrub density increased over time with succession; the birds were absent in nearby unburned conifer forest. The findings in those studies are consistent with our results.

The Yellow Warbler is a California bird species of special concern (Heath 2008, Shuford and Gardali 2008) and has experienced regional and local declines in the state. While much focus on their management has been on riparian habitat, and such focus is critical, their occurrence in montane chaparral throughout much of the Sierra Nevada, the typically low densities of cowbirds there, and the opportunities 
for forest management to benefit this habitat lead us to suggest the inclusion of montane chaparral populations in future management actions for this species.

\section{ACKNOWLEDGMENTS}

We are grateful to all the PRBO interns and staff who collected these nest, vegetation, and point-count data. We also thank Geoff Geupel for project guidance, Nat Seavy and Scott Jennings for statistical advice and assistance with Program R, Sacha Heath for sharing her insights on Yellow Warblers in California, and Coye Burnett of the Lassen National Forest for providing the management history of our nest plots. Funding for the various projects from which our data were derived was provided by Region Five of the U.S. Forest Service, HFQLG monitoring funds, the National Fire Plan, and the Lassen National Forest. We thank the Sierra Nevada Research Center of the Pacific Southwest Research Station of the Forest Service and the Lassen and Plumas National Forest staff for all their assistance with and long-term support of these projects. This is PRBO Contribution Number 1706.

\section{Literature Cited}

Altman, B., AND J. Hagar. 2007. Rainforest birds: a land manager's guide to breeding bird habitat in young conifer forests in the Pacific Northwest. U.S. Geological Survey, Scientific Investigations Report 2006-5304.

BeEdy, E.C., AND S.L. Granholm. 1985. Discovering Sierra birds. Yosemite Natural History Association and Sequoia Natural History Association, CA.

Buckland, S.T., D.R. Anderson, K.P. Burnham, AND J.L. LAAKE. 1993. Distance sampling: estimating abundance of biological populations. Chapman and Hall, London, United Kingdom.

[CalWater] California Interagency Watershed MapPING Committee. 1999. California Watersheds. Version 2.2. Available from: http://www.ca.nrcs.usda .gov/features/calwater/.

Ehrlich, P.R., D.S. Dobkin, and D. Wheye. 1988. The birder's handbook. Simon \& Schuster, New York, NY.

[ESRI] Environmental Systems Research Institute. 2000. ArcView GIS 3.2a. Redlands, CA.

GaInES, D. 1992. Birds of Yosemite and the East Slope. 2nd edition. Artemisia Press, Lee Vining, CA.

Grinnell, J., J. Dixon, and J.M. Linsdale. 1930. Vertebrate natural history of a section of northern California through the Lassen Peak region. University of California Publications in Zoology 35.

Grinnell, J., AND A.H. Miller. 1944. The distribution of the birds of California. Pacific Coast Avifauna 27.

Heath, S.K. 2008. Yellow Warbler (Dendroica petechia). Species account in W.D. Shuford and T. Gardali, editors, California bird species of special concern: a ranked assessment of species, subspecies, and distinct populations of birds of immediate conservation concern in California. Studies of Western Birds 1. Western Field Ornithologists, Camarillo, California, and California Department of Fish and Game, Sacramento, CA.

HFQLG. 1999. Herger-Feinstein Quincy Library Group Forest Recovery Act, final environmental impact statement. USDA Forest Service, Pacific Southwest Region, Vallejo, CA. Available from: http://www.fs .fed.us/r5/hfqlg/publications/1999_feis/TOC.htm

HutTo, R.L. 1995. Composition of bird communities following stand-replacement fires in Northern Rocky Mountain (U.S.A.) conifer forests. Conservation Biology 9:1041-1058.

King, A.M., J.R. King, A.L. Holmes, And N. Nur. 2001. Songbird monitoring in Almanor Ranger District (Lassen National Forest) and Lassen Volcanic National Park: 1997-1999. A final PRBO report to the U.S. Forest Service and the National Park Service. PRBO Contribution Number 949.

Lowther, P.E., C. Celada, N.K. Klein, C.C. Rimmer, AND D.A. SpECTOR. 1999. Yellow Warbler (Dendroica petechia). Account No. 26 in A. Poole and F. Gill, editors, The birds of North America. Academy of Natural Sciences, Philadelphia, PA, and American Ornithologists' Union, Washington, DC.

MARTIN, T.E. 1992. Breeding productivity considerations: what are the appropriate habitat features for management? Pages 455-473 in J.M. Hagan and D.W. Johnston, editors, Ecology and conservation of neotropical migrants. Smithsonian Institution Press, Washington, DC.

Martin, T.E., And C. Conway. 1995. BBIRD field protocol: Breeding Biology Research and Monitoring Database. Montana Cooperative Wildlife Research Unit, Missoula, MT.

Martin, T.E., And G.R. Geupel. 1993. Nest monitoring plots: methods for locating nests and monitoring success. Journal of Field Ornithology 64:507-519.

MAYFIELD, H.F. 1961. Nesting success calculated from exposure. Wilson Bulletin 73:255-261.

1975. Suggestions for calculating nest success. Wilson Bulletin 87:456-466.

Moran, M.D. 2003. Arguments for rejecting the sequential Bonferroni in ecological studies. Oikos 100:403-405.

NAGEL, T.A., AND A.H. TAYLOR. 2005. Fire and persistence of montane chaparral in mixed conifer forest landscapes in the northern Sierra Nevada, Lake Tahoe Basin, California, USA. Journal of the Torrey Botanical Society 132:442-457.

ORTEGA, C.P. 1998. Cowbirds and other brood parasites. University of Arizona Press, Tucson, AZ.

Ralph, C.J., G.R. Geupel, P. Pyle, T.E. Martin, and D.F. DESANTE. 1993. Field methods for monitoring landbirds. General Technical Report PSW-GTR 144, USDA Forest Service, Pacific Southwest Research Station, Albany, CA.

Raphael, M.G., M.L. Morrison, and M.P. Yoder-WiLLIAMS. 1987. Breeding bird populations during twentyfive years of postfire succession in the Sierra Nevada. Condor 89:614-626.

Rice, W.R. 1989. Analyzing tables of statistical tests. Evolution 43:223-225.

RoHwER, S. 2004. Using age ratios to infer survival and despotic breeding dispersal in hybridizing warblers. Ecology 85:423-431. 
Salgado-Ortiz, J., P.P. Marra, T.S. Sillett, and R.J. Robertson. 2008. Breeding ecology of the Mangrove Warbler (Dendroica petechia bryanti) and comparative life history of the Yellow Warbler subspecies complex. Auk 125:402-410.

Shuford, W.D., and T. GaRdali, EDITORS. 2008. California bird species of special concern: a ranked assessment of species, subspecies, and distinct populations of birds of immediate conservation concern in California. Studies of Western Birds 1. Western Field Ornithologists, Camarillo, CA, and California Department of Fish and Game, Sacramento, CA.

SiegEL, R.B., AND D.F. DeSAnTE. 2003. Bird communities in thinned versus unthinned Sierran mixed conifer stands. Wilson Bulletin 115:155-165.

SNFPA. 2004. Sierra Nevada Forest Plan Amendment, final supplemental environmental impact statement USDA Forest Service, Pacific Southwest Region, Vallejo, CA. Available from: http://www.fs.fed.us/r5/ snfpa/final-seis/rod/

Stephens, S.L., R.E. Martin, and N.E. Clinton. 2007. Prehistoric fire area and emissions from California forests, woodlands, shrublands, and grasslands. Forest Ecology and Management 251:205-216.

TAYLOR, A.H. 2000. Fire regimes and forest changes in mid and upper montane forests of the southern Cascades, Lassen Volcanic National Park, California, USA Journal of Biogeography 27:87-104.

TAYlOR, A.H., AND C.N. SKINNER. 2003. Spatial patterns and controls on historical fire regimes and forest structure in the Klamath Mountains. Ecological Applications 13:704-719.

VANKAT, J.L., AND J. MajoR. 1978. Vegetation changes in Sequoia National Park, California. Journal of Biogeography 5:377-402.

Verner, J., AND T.A. LARSON. 1989. Richness of breeding bird species in mixed-conifer forests of the Sierra Nevada, California. Auk 106:447-463.

Received 10 May 2009 Accepted 24 February 2010 